\title{
El Marco Narrativo de La Vorágine
}

El lector que acaba de terminar $L a$ vorágine y se pone a reflexionar sobre su mérito y significado se dará cuenta en seguida de la inestimable importancia de su narrador y protagonista; Arturo Cova. Este individuo de tan definido carácter y rasgos personales tan especiales domina absolutamente la novela. Se revela perfectamente ante el lector, quien, después de concluir la obra, conoce mejor a Arturo Cova de lo que éste se conoce a sí mismo. Todas las idiosincrasias de Cova, todas sus manías y obsesiones, no sólo son parte de su carácter: son parte de la narración. La obra se impregna del espíritu y mentalidad covianos hasta cobrar forma y definirse mediante estas particularidades. Al mismo tiempo hace falta subrayar la singular aptitud de Cova para su faena: es hombre de letras, poeta que no ha logrado destacarse todavía, y como escritor tiene varias nociones acerca de los modos más eficaces de expresar sus ideas. Su manuscrito, pues, lo dota de alardes verbales, dramatismo y valores literarios que tal vez le recaben la fama que no había gozado como poeta. Pero a fin de comprender en su debida perspectiva el documento de Cova-núcleo y casi totalidad de la novela-conviene examinar primero la estructura que lo enmarca.

La obra comienza con un "fragmento de la carta de Arturo Cova", en que él lamenta la pérdida de su naciente notoriedad y su forzosa huida de la ciudad. Este tema-la posible pérdida de su gloria literaria, relacionada con una creencia en una especie de destino responsable por su desgracia-va a ser una de las preocupaciones centrales de Cova mientras redacta su manuscrito. La colocación del fragmento, por lo tanto, al principio de la novela ${ }^{22}$ encabeza admirablemente la obra, ofreciendo un anticipo no sólo del carácter del narrador, sino también de su

\footnotetext{
${ }^{1}$ José Eustasio Rivera, La vorágine, (13ª ed.; Buenos Aires: Editorial Losada, 1972); p. 7. Las demás referencias a páginas serán a esta edición.

${ }^{12}$ Una aclaración, antes de entrar plenamente en la discusión: el término "novela" se refiere a la obra íntegra, producto de su autor. Lo que escribe Cova, en cambio, no es tanto novela como simple narración de hechos positivos ocurridos dentro del marco de su existencia. Pero sobre todo, y como se verá, lo que escribe Cova solo no es la novela La vorágine.
} 
estilo. Pero ¿quién ha sido capaz de proporcionar al lector esta pequeña vista anticipada del contenido? ¿Cuál ha sido su intención: interesar al lector con un trozo preliminar agorero de las peripecias novelescas, o quizá incluir un epígrafe en honor del infortunado Cova? Y en último término, ¿con qué autoridad decide publicar tan sólo una parte de la carta, dejando de revelar el contenido entero?

Las dudas del lector se aplacan al volver la página y encontrarse con un Prólogo firmado por José Eustasio Rivera. El prólogo tiene la forma de una esquela dirigida a un ministro del gobierno, comunicándole unos datos sobre el manuscrito de Cova. El juego literario que utiliza Rivera aquí es sugestivo e involucra ciertas complicaciones que importa comentar. El truco responde al afán del autor de dar apariencia de realidad a su ficción, de estrechar el lazo entre lector y mundo novelado. ${ }^{3}$ Rivera, hombre de carne y hueso, se dirige a un funcionario, y estos dos individuos tratan el caso de Cova, instalando así también a éste en el plano real. Un diario escrito por Cova ha llegado a poder del ministerio, y el ministro ha nombrado a Rivera para que lo revise y publique. Rivera, si bien se introduce en su obra, se deshace de toda ligazón con su concepción y nacimiento. Hace que el ministro parezca responsable de su existencia, y remacha el punto al opinar "que este libro no se debe publicar antes de tener más noticias de los caucheros" ( $p$. 9). Rivera se zafa asimismo del contacto directo con el lector: su correspondencia con el ministro es una invención suya para dar la impresión de que el lector se asoma a una comunicación no dirigida a él. El autor se desvive por parecer un partícipe casual en la preparación del libro, por crear la ilusión de que Cova no es creación suya sino un ser independiente y autosuficiente.

Ahora, si el cónsul de Colombia en Manaos llevó el documento al ministro, y si éste ordenó sacarlo a luz, ¿cuál ha sido el papel de José Eustasio Rivera-siempre dentro del artificio ingeniado por él mismo en el Prólogo-en brindarlo al público? "He arreglado para la publicidad los manuscritos de Arturo Cova", explica, todavía al ministro. "En esas páginas respeté el estilo y hasta las incorrecciones del infortunado escritor, subrayando únicamente los provincialismos de más carácter" (p. 9). Todo esto está sutilmente expresado. Un vocablo que exige particular consideración es arreglar: al arreglar el escrito de Cova, ¿qué libertades se permitiría? Evidentemente se estimó capaz de suprimir una porción de la carta que dio a conocer anteriormente. ¿Se tomaría semejante libertad tratándose de "los manuscritos"? ¿Cuántos manuscritos hay, por cierto? ¿Se trata de una obra escrita en varias etapas y distintos formatos? Al afirmar que "respeta el estilo" de Cova, ¿qué implica: que copió textualmente su modelo, o que, basándose en las peculiaridades de su prosa, nos ofrece una versión

\footnotetext{
${ }^{3}$ Ya hizo notar Angel Valbuena Briones este propósito del autor en su Literatura hispanoamericana ( ${ }^{\mathrm{a}}$ ed.; Barcelona: Editorial Gustavo Gili, 1967), p. 386, al llamar la atención sobre tres fotografías que aparecen en la edición Cromos de La vorágine:

1. "Arturo Cova en las barrancas del Guaracú", tomada por la madona Zoraida Ayram;

2. "Un cauchero", que hace una incisión en el árbol;

3. "El cauchero Clemente Silva".
} 
parafrástica? Mas el estilo no es lo único que respeta: también respeta "las incorrecciones del infortunado escritor". Otro caso de insistencia sobre la autonomía de Cova, y a la vez, iqué manera más maravillosa de librarse de la culpa de cualquier defecto en el estilo! No importa el papel que haya desempeñado Rivera en la redacción de la versión que tenemos ante nosotros: a Cova hay que reprocharle toda imperfección. Respecto a su aseveración de que "subraya" los provincialismos del original, hay que entenderla literalmente, ya que estas expresiones en el texto aparecen en bastardillas.

Rivera promete un epílogo al final del libro si el ministro le proporciona los datos que esclarezcan el desenlace de la historia referida en el manuscrito. Se ganan así dos ventajas literarias: el autor se aleja aun más de la actuación de su protagonista - un funcionario gubernamental tendrá que informarle sobre un personaje que es en realidad total invención del mismo Rivera-y establece simultáneamente una especie de anticipación o curiosidad de parte del lector. $O$ sea, Rivera, en el momento de arreglar los manuscritos de Cova, no sabe el final que éste haya tenido. Se iguala con el lector, quien tampoco durante su contacto con el manuscrito - la lectura - sabe cómo finalizará el desgraciado héroe. En el epílogo mismo Rivera guarda su habitual reserva aparente respecto de lo que se le ha encargado. Se limita a dar aviso, algo secamente, de la llegada de un telegrama:

Hace cinco meses búscalos en vano Clemente Silva.

$\mathrm{Ni}$ rastro de ellos.

¡Los devoró la selva! (p. 261)

Según lo dispone el autor, la emoción nos la imparte el cónsul, el-que manda el telegrama. Rivera se abstiene de proferir la menor opinión sobre el asunto. Se ha esforzado en todo momento por mantenerse aparte del manuscrito y su contenido, por hacer el papel del simple comentarista desapasionado. La eficacia de estos esfuerzos dependerá, claro está, del empeño que ponga cada lector en comprender la novela, en salvar los obstáculos puestos en su camino por una mano artera. Y resulta que al lector más sagaz, el capaz de ver todas estas mañas bajo la superficie, le pasa algo hermoso: puede olvidarlo todo y aceptar dócilmente la mentira. El lector más privilegiado de La vorx́gine es el que reconoce las intrincadas estructuras e intenciones de la obra, pero arrincona estos conocimientos para participar en ella plenamente y sentir el entusiasmo e interés que Rivera quiso disimular. El lector más privilegiado de La vorágine es el que puede analizar la técnica literaria de Arturo Cova con la misma sinceridad y desparpajo que usó al estudiar la de José Eustasio Rivera. Lo haremos en seguida.

El manuscrito de Cova es un documento largo, dividido en tres partes. Esta división se basa en la materia tratada: primera parte, los llanos; segunda parte, la selva; tercera parte, las caucherías. Pero para lector y narrador hay una división más importante. El lector que ha estado siguiendo asiduamente las aventuras de Cova, al llegar a determinado punto de su lectura, tiene que preguntarse: ¿cuándo escribió Cova estas páginas? O sea, ¿cuál es la perspectiva 
temporal con que Cova relata su historia? Hay varios momentos en que el lector está particularmente consciente de esta perspectiva. Expresiones como las siguientes implican un claro tiempo presente en que el narrador escribe su historia y desde el cual examina y juzga los actos y pensamientos que describe:

Confieso, arrepentido, que en aquella semana cometí un desaguisado. Di en enamorar a la niña Griselda, con éxito escandaloso.

Y esa risa...me pareció vengativa, torturadora, y aun al través de los días que corren, me repite su mueca desde ultratumba y me estremece de pavor. (pp. 90-91)

El fantasma impávido del suicidio, que sigue esbozándose en mi voluntad, me tendió sus brazos esa noche... (p. 115)

Claramente, desde aquel día tuve el presentimiento de lo fatal. Todas las desgracias que han sucedido se me anunciaron en ese momento. (p. 135)

¿Cuál es el momento en que Cova confiesa estos sentimientos, y cuáles son los dias que corren, durante los cuales recuerda y analiza momentos pasados? La respuesta viene súbitamente en la página 224:

Va para seis semanas que, por insinuación de Ramiro Estévanez, distraigo la ociosidad escribiendo las notas de mi odisea, en el libro de Caja que el Cayeno tenía sobre su escritorio como adorno inútil y polvoriento. Peripecias extravagantes, detalles pueriles, páginas truculentas forman la red precaria de mi narración, y la voy exponiendo con pesadumbre, al ver que mi vida no conquistó lo trascendental y en ella todo resulta insignificante y perecedero.

Esta división temporal es clave: para el lector porque por fin se resuelven sus dudas en cuanto a la redacción del manuscrito; para Cova porque mientras todo lo anterior a este momento lo había escrito como recuerdo de sucesos pretéritos, el resto del manuscrito tendrá la forma del diario tradicional, describiendo los actos de día en día, a medida que ocurren. Por consecuencia, Cova tiene dominio total sobre lo que llamaremos el primer tiempo o fase del manuscrito-páginas 11-224-porque en cualquier instante de la redacción de esta fase el narrador sabe todos los datos que puede incluir en ella. Al contar su llegada a La Maporita, por ejemplo, sabe que volverá Franco, que incendiará su casa, y que los dos saldrán en busca de sus respectivas mujeres. Esta conciencia de un cuerpo cerrado de acontecimientos le permite al narrador proceder con confianza y soltura dentro de este primer tiempo, que él controla completamente, y hace posible el empleo de un recurso literario: la prefiguración. Cova, sabiendo que Correa sentirá nostalgia al escuchar el canto del píapoco (p. 116), se toma la molestia de explicar cuidadosamente, con la ayuda de Sebastiana, las singulares 
propiedades del pájaro (p. 36). Los ejemplos son numerosos. ${ }^{4}$ Pero a partir del punto en el manuscrito que corresponde a la página 224 del libro, Cova, al igual que el lector, desconoce el rumbo que tomará su suerte. El cambio de mira es recalcado por el empleo de verbos en tiempo presente y por repetidas alusiones a su nuevo modo de escribir: "Hoy escribo estas páginas en el Río Negro..." (p. 246), "Esto lo escribo aquí en el barracón de Manuel Cardoso..." (pp. 256-257). El tono ordenado de la primera fase ha cedido a la desesperación y ansia de no saber lo que pasará:

¡Hace cinco días que se hallan ausentes, y la incertidumbre me vuelve loco! (p. 239)

La misma angustia la experimenta el lector, sintiéndose más cerca que nunca del pobre Cova, y sufriendo de la misma duda: "YYo no sé lo que va a pasar!" (p. 256).

En seguida de averiguar el lector el esquema temporal de la composición del manuscrito, se entera de su finalidad. Según Cova, es la siguiente:

Erraría quien imaginara que mi lápiz se mueve con deseos de notoriedad, al correr presuroso en el papel tras de las palabras para irlas fijando sobre las líneas. No ambiciono otro fin que el de emocionar a Ramiro Estévanez con el breviario de mis aventuras, confesándole por escrito el curso de mis pasiones y defectos, a ver si aprende a apreciar en mí lo que en él regateó el destino, y logra estimularse para la acción, pues siempre ha sido provechosísima disciplina para el pusilánime hacer confrontaciones con el arriscado. (p. 225)

El narrador declara que su narración va dirigida hacia una sola persona, su amigo Ramiro Estévanez. Evidentemente el lector se sorprende al recibir la noticia, porque de hecho. no había topado con pista alguna que delatara tal propósito. Nunca Cova se había dirigido a Ramiro directamente, ni siquiera lo había mencionado hasta el momento en que entró en la acción. ¿Será cierto lo que pretende hacernos creer? La única contestación posible es una sonora negativa. Aunque en las páginas que siguen inmediatamente Cova procura apuntalar su aseveración, ${ }^{5}$ no nos va a convencer. La prueba más eficaz de la falsedad del aserto es la mera existencia de esta explicación. Si Ramiro Estévanez va a ser el único lector del manuscrito, ¿para qué amonestar a lectores que nunca leerán el

${ }^{4}$ Piénsesè en el bayetón rojo, mencionado por Cova al contar su llegada a La Maporita (p. 26) y usado por Barrera como señal (p. 53); y el cuero de tigre, que guardaba el viejo Zubieta bajo su chinchorro (p. 59), y que servirá para causar el barajuste del ganado (p. 70). El caso de los zarcillos de esmeralda de la niña Griselda, ambicionados por Barrera (p. 40), es distinto, puesto que los volvemos a encontrar en poder de la madona Zoraitda Ayram (p. 236), o sea, en la segunda fase del manuscrito. La prefiguración no puede ser en este caso obra de Cova, aunque sí lo es del autor Rivera.

${ }^{5}$ Se dirige a Estévanez en tono confidencial, después que sus compañeros le aconsejan matar a su enemigo:

"Si Barrera está por aquí, ¿cuál es mi deber?"

- "iMatarlo, matarlo!"

Y tú mismo, Ramiro Estévanez, sostienes el fatal consejo... (p. 237) 
mamotreto? Obviamente Cova está pensando en otros lectores, y aunque no quiera reconocerlo, es hacia estos lectores a quienes el manuscrito va encaminado. ¿No se nos hace conocido este distanciamento entre narrador y lector, creado por aquél? Cova nos está diciendo: "Esto no es para ustedes. Es para Ramiro Estévanez. El me inspiró a que lo escribiera." Anteriormente Rivera nos dio a entender: "Esto no lo hago por ustedes. Lo hago por el ministro. El me sugirió que revisara el manuscrito." En ambos casos el escritor se separa de su verdadero lector. Rivera lo hace adrede, por dar apariencia verosímil a su obra. ¿Por qué lo hace Cova? Tal vez quisiera esquivar las críticas de incontables lectores-críticas sobre su persona o su estilo-explayando sus "pasiones y defectos" a la vista de un solo conocido. O quizá comenzara su labor con la intención de dirigir sus comentarios a su camarada y se dejara llevar por la tentación de novelar, de dotar su obra de interés novelístico. El único apoyo que parece encontrar la afirmación de Cova es el simple hecho de que la madona y El Váquiro, y la mayoría de los demás personajes que pudieran tener acceso al documento, son analfabetos. Al introducir a Estévanez en la acción evocada, el narrador habla de Ramiro como de cualquiera:

Un singular afecto me ligó siempre a Ramiro Estévanez. Hubiera

querido ser su hermano menor. Ningún otro amigo logró inspirarme aquella confianza... (p. 214)

No hemos de creer que esto esté dicho al mismo Estévanez. El representa, como sugiere Cova, meramente un confidente: le infunde la confianza necesaria para escribir sus apuntes, pero no será el único lector de ellos, una vez escritos. Si Cova tuvo intento de desahogarse con Estévanez, su determinación sufre una evidente modificación. La inclusión de la historia de la matanza realizada por Funes el 8 de mayo de 1913 (pp. 228-234), contada por Estévanez, testigo ocular de la tragedia, evidentemente sobre en un manuscrito dirigido al propio Estévanez. Hacia el final Cova escribe:

Toda la madrugada estuve llorando, sin más compañía que la de

Ramiro, quien sentado a mi diestra en el chinchorro, no profería palabra.

(p. 251)

$Y$ aun después de despedirse de Estévanez, el narrador continúa su tarea:

vi por última vez a Ramiro Estévanez y a la madona Zoraida Ayram,

sobre la barranca del puertecito, llorosos, trémulos, espantados. (p. 254)

Siguen varias entradas en el diario, y desde luego, Cova no deja el manuscrito en manos de su amigo. No tenemos ningún indicio concreto de que Estévanez-quien, por más señas, padece un grave deterioro de la vista y mantiene los ojos cubiertos con trapos-jamás haya leído el documento que supuestamente está dedicado a él y a nadie más.

Ahora, ¿qué implica todo esto? Ya que Cova nos ha dicho algo que no es cierto, ¿hay que desconfiar de todo lo que escribe? Sí y no. Cova no ha mentido en la acepción usual de la palabra. Ha dicho algo que quisiera que fuese verdad: le halaga pensar que lleva su diario sólo para el provecho del "pusilánime" 
Estévanez, su constante "amigo mental". ${ }^{6} \mathrm{Su}$ orgullo le impide ver claramente que sí siente aquellos "deseos de notoriedad" de que reniega. Hemos podido probar la falacia de su declaración mediante la lógica, el examen del texto, y la comprensión del carácter del narrador. Mientras no diga otra cosa que pueda negarse por medio de estos criterios nos incumbe creer lo que nos cuenta. Pero estamos advertidos, y tendremos la oportunidad, en más de una ocasión, de demostrar la falsedad de los razonamientos de Cova, en aquellos casos donde la vida interior del personaje parece deformar la realidad objetiva de las situaciones.

Entonces en La vorágine tenemos un caso insólito de confusión o modificación de identidades, tanto del autor Rivera como del narrador Cova. Rivera se ficcionaliza primero en el momento de introducirse en el ámbito novelesco de su propia creación: aquel José Eustasio Rivera que firma el Prólogo es un trasunto de la persona del novelista, la imagen en el espejo si se quiere, un personaje libresco de vida e identidad independientes. Lo realmente notable es que al querer afianzar firmemente a su personaje Cova en el plano real, Rivera se ha consignado él mimso al reino de la ficción. Pero a fin de cuentas, esto es natural: cualquier escritor que hace ficción basada en experiencias e ideologías personales lo hace. Rivera se encuentra ficcionalizado también, hasta cierto grado, en el personaje de Cova. Lo que no debemos dejar de ver claramente es que el mismo Cova, dentro de su propio marco vital, se ficcionaliza. Es natural, acabamos de afirmarlo. No importa que en su diario Cova trate hechos para él reales: al consagrarse al recinto de su obra se convierte inapelablemente en personaje literario. Pero la proyección que en su manuscrito hace de sí, de su papel como escritor, es esencialmente falsa. Presenta aquello que quisiera ser y hacer; disfraza la verdadera naturaleza de su comunicación literaria. Ahora podemos percibir que ese Arturo Cova que ama, lucha, busca y se frustra, es ficcionalización de otro Arturo Cova, el escritor que estila y estiliza un curioso documento de dudoso destino; y que los dos son, a su vez, ficcionalizaciones de la persona real del autor. Para complicar esta estructura, tenemos la intermediación del personaje José Eustasio Rivera-ficcionalización del novelista en su solo papel de escritor-y la dedicación del manuscrito a un auditorio falso en todos los niveles. Los destinatarios aparentes del manuscrito son espejismos todos ellos: el cónsul, el ministro, y sobre todo aquel Ramiro Estévanez-o Esteban Ramírez-que él mismo es un caso de identidad ambigua. La identidad prestada o simulada es la regla en esta novela: ello nos explica la facilidad con que Cova asume el papel y perspectiva de otros personajes-Helí Mesa, Clemente Silva, Ramiro Estévanez-al narrar episodios que afectan directamente a estos individuos.

Para completar nuestro examen de la estructura narrativa de La vorágine,

6 Cova había declarado, a propósito de Estévanez: “De tal suerte llegué a habituarme a comparar nuestros pareceres, que ya en todos mis actos me preocupaba una reflexión: ¿Qué pensaría de esto mi amigo mental?" (p. 214) 
volvamos brevemente a aquel "fragmento de la carta de Arturo Cova" que inicia la novela. Esta carta va dirigida, según parece, al cónsul de Colombia en Manaos, individuo al que Cova no conoce. ¿Es éste el lugar para quejarse amargamente de su suerte, para revelar datos de su vida íntima y afectiva, para perorar en contra del destino adverso? No. Cova habla más bien a:

...Los que un tiempo creyeron que mi inteligencia irradiaría extraordinariamente...los que se olvidaron de mí...los que al recordarme alguna vez piensen en mi fracaso...sepan que el destino me desarraigó de la prosperidad incipiente y me lanzó a las pampas... (p. 7)

Es claro que Cova, como siempre, piensa en otros lectores. Ni Cova escribe para el cónsul, ${ }^{7}$ ni Rivera incluye este trozo de la carta a instancias del ministro: todo va encaminado hacia el lector, hacia nosotros. Y es en esta ruta comunicativa tortuosa y disimulada, siempre cuidadosamente trazada, donde reside el valor de La vorágine como creación artística, donde la novela deja de ser panfletaria protesta propagandística y comienza a ser literatura.

University of Texas, El Paso

RICHARD FORD

7 Conviene recordar las circunstancias de la redacción de esta carta. Escribe Cova: "me encerré en la oficina del patrón, y en compañía de Ramiro Estévanez, redacté para nuestro cónsul el pliego que debía llevar don Clemente Silva, una tremenda requisitoria, de estilo borbollante y apresurado como el agua de los torrentes" (p. 214). La escena sintetiza perfectamente la concepción y estructura de la narración: la presencia de Estévanez es necesaria, como siempre, para que Cova haga literatura; pero el resultado-el mismo "estilo borbollante y apresurado" del manuscrito total-se ofrece a un público lector más amplio que el señalado. 